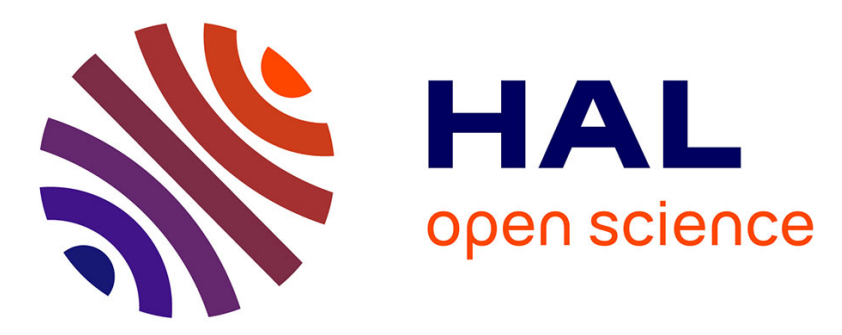

\title{
An analysis of large-scale transmission power blackouts from 2005 to 2016
}

Maxime Velay, Meritxell Vinyals, Yvon Besanger, Nicolas Retière

\section{To cite this version:}

Maxime Velay, Meritxell Vinyals, Yvon Besanger, Nicolas Retière. An analysis of large-scale transmission power blackouts from 2005 to 2016. 2018 53rd International Universities Power Engineering Conference (UPEC), Sep 2018, Glasgow, United Kingdom. pp.8541901, 10.1109/UPEC.2018.8541901 . hal-02330748

\section{HAL Id: hal-02330748 \\ https://hal.science/hal-02330748}

Submitted on 18 Nov 2019

HAL is a multi-disciplinary open access archive for the deposit and dissemination of scientific research documents, whether they are published or not. The documents may come from teaching and research institutions in France or abroad, or from public or private research centers.
L'archive ouverte pluridisciplinaire HAL, est destinée au dépôt et à la diffusion de documents scientifiques de niveau recherche, publiés ou non, émanant des établissements d'enseignement et de recherche français ou étrangers, des laboratoires publics ou privés. 


\title{
An analysis of large-scale transmission power blackouts from 2005 to 2016
}

\author{
M. Velay ${ }^{\mathrm{a}, \mathrm{b}}, \mathrm{M}$. Vinyals ${ }^{\mathrm{a}}$, Y. Besanger ${ }^{\mathrm{b}}$, N. Retiere ${ }^{\mathrm{b}}$ \\ ${ }^{a}$ CEA, LIST, Laboratoire d'Analyse des Données et d'Intelligence des Systèmes, Gif-sur-Yvette, 91191 France \\ ${ }^{b}$ Univ. Grenoble Alpes, CNRS, Grenoble INP ${ }^{0}$, G2Elab, 38000 Grenoble, France
}

\begin{abstract}
Major power failures, i.e. power transmission blackouts, have large technical, economic, and social consequences in the affected areas. As power systems evolve with new customs, technologies and regulations, continuous analysis of recent blackouts is crucial for identifying new trends and for updating prevention measures.

In this paper, we analyze 9 major blackouts that happened between 2005 and 2016, among them some of the largest blackouts of all times, to complete previous blackout studies. We classify these blackouts depending on the conditions and events before and during the cascades and identify their main characteristics. Our analysis reveals that blackouts from the last decade tend to exhibit different features than precedents; in particular they happened in periods of normal loading with some important equipment out of service and with highly dependent transmission systems regions. Moreover, recent blackouts show a greater tendency to enter directly into the fast cascade, leaving system operators with hardly any time to take any countermeasure.
\end{abstract}

Keywords: Large scale blackout, cascading failure, cascade analysis, power system stability, cascade prevention

\section{Introduction}

Our societies are more dependent on electricity than ever, thus any power outage, i.e. blackout, has a major economic and social impact. For example, in 2011, the blackout of southern California, Arizona and Baja California regions [1] cost around 100 million dollars [2].

The actual path to a blackout involves a complex, interdependent sequence of events. As depicted in Fig. 1, following $[3,4,5]$, the progression of the cascade of events can be divided into 4 phases. The first phase is called (I) preconditions and it includes the period before any major disturbance, when the power system is in a stable state (i.e. all technical and operational constraints are respected). The blackout in itself starts by a set of initiating events that disturbs the power system and makes it unstable. This initial disturbance propagates in the form of a cascade of events that can last from a few seconds to several hours. The cascade can usually be separated into two phases: (II) steady state (also known as slow) and (III) fast (also known as high-speed). When the blackout reaches its final state (i.e. when the cascade ends), unserved loads, power generation shed and the number of people impacted can be evaluated (i.e. to be considered a blackout either part or the entire system should have collapsed). The (IV) restoration of the system

\footnotetext{
Email addresses: maxime. velay@cea.fr / maxime.velay@g2elab.grenoble-inp. fr (M. Velay), meritxell.vinyalsecea.fr(M. Vinyals),

starts from this point and takes from tens of minutes to several days to achieve full recovery.

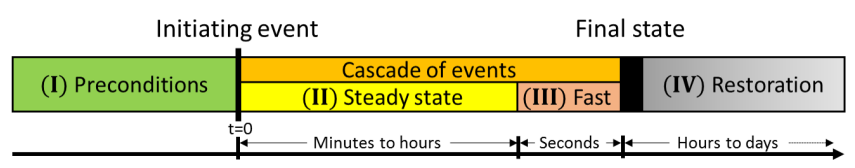

Figure 1: Division of the progression of a blackout into phases as proposed in [5].

Continuous data analysis of previous blackouts is crucial for controlling their perpetual evolution as well as for drawing effective recommendations for their prevention $[6,7,8]$. Consequently, the vulnerability of power systems and, in particular, previous blackouts have been widely studied to improve power systems reliability $[9,10,11,12]$. Despite this activity in the field, none of the existing studies cover the last decade period (i.e. from 2005 to 2016). This period during which the power electricity grid experienced significant evolutions (e.g., energetic transition, instrumentation and control automation and demand increase, among others [11]) includes some of the largest blackouts in history.

Against this background, this paper analyzes 9 recent major power blackouts that occurred between 2005 and $2016^{1}$ to complete previous studies. Table 1 provides details for each of these blackouts: the abbreviation used in the rest of the paper, the date, the location and the main references on which we based our analysis. Note that the development of these power systems was not done at the same time nor with the same technologies

${ }^{1}$ These blackouts were selected based on the availability of data and reports. 
in all countries; in particular, the analysis contains only two long-time developed power system, i.e. USA11 and AUSTR16.

Table 1: Details of the 8 blackout analyzed.

\begin{tabular}{|c|c|c|c|}
\hline Abbreviation & Date & Location & References \\
\hline \hline INDO05 & $2005 / 08 / 18$ & Indonesia & {$[13]$} \\
\hline COLOM07 & $2007 / 04 / 26$ & Colombia & {$[14,15,16]$} \\
\hline BRAZ09 & $2009 / 11 / 10$ & Brazil & {$[17,18,19]$} \\
\hline BRAZ11 & $2011 / 02 / 04$ & Brazil & {$[20,19]$} \\
\hline USA11 & $2011 / 09 / 08$ & USA/Mexico & {$[1]$} \\
\hline CHILE11 & $2011 / 09 / 24$ & Chile & {$[21]$} \\
\hline INDIA12 & $2012 / 07 / 30-1^{2}$ & India & {$[22]$} \\
\hline TURK15 & $2015 / 03 / 31$ & Turkey & {$[23]$} \\
\hline AUSTR16 & $2016 / 09 / 28$ & Australia & {$[24]$} \\
\hline
\end{tabular}

Our objective with this analysis is to identify the more frequent characteristics of these recent blackouts to update and contribute to the understanding of cascading events, which in its turn will allow reliability standards and defense plans to evolve in consequence. To that end, we describe, classify and make a careful comparison of these blackouts with the findings and conclusions of previous studies, especially those that focus on different time periods. In addition, as highlighted in [6], a major issue while simulating blackouts is to choose the cases to be studied, we thus provide a sketch of a representative scenario built on our analysis.

This paper is organized as follows. First, we review the related literature in Section 2. Afterward, the rest of the paper is organized following the different blackout phases: Section 3 analyzes the most relevant preconditions that enabled these blackouts to happen, Section 4 describes the initiating events and Section 5 analyzes the cascades of events that followed. The paper concludes in Section 6 with the main findings from this analysis and discussion of future work.

\section{Related Work}

Given the large economic and social impact of blackouts, a variety of methods have been proposed in the power system literature to study this challenging topic. Baldick et al. [6] and Vaiman et al. [7] provide comprehensive reviews on this area and discuss the main methods for cascading failure analysis and simulations. Of particular interest here, both works highlight the importance of previous blackout data analysis for the progress of the field towards effective methods for blackout risk assessment. Consequently, several studies have been published on the analysis of the cascading failures, each covering a

\footnotetext{
${ }^{2}$ Two blackouts happened on two consecutive days. Operators had time to restore the system before the second blackout happened. Since pre-conditions and initiating events are of same nature, we will only develop the differences in the description of the cascade.
}

specific time period. For instance, in [9], Atputharajah et al. describe the causes and the development of 9 blackouts that happened between 1965 and 2007, highlighting the role of reactive power reserves, which ensure voltage stability, and of the voltage angle phases difference, which keep regions synchronized. In a similar line of work, Yamashita et al. [10] analyze the causes and the sequence of events that led to 4 blackouts within the period from 1996 to 2006 to find patterns of sequences. They discuss the control actions that could prevent cascade of events, either system operation or emergency control, and emphasize the importance of overload cascades mitigation since it often leads to system splitting. Further, Andersson et al. summarizes in [11] three power blackouts that happened in 2003: in North America, in Sweden \& Denmark and in Italy. The paper draws recommendations and details how new technologies, like flexible alternating current transmission system or high-voltage direct current, can improve power systems security and stability.

Blackouts have been the focus of discussion of two panel sessions [25, 26] and of a series of invited papers [27, 28, 29, 30, 31, 32] in the IEEE Power \& Energy Magazine September / October 2006, both sponsored by the IEEE Power System Dynamic Performance Committee and Blackout task force. In its final report [4], the task force summarizes the causes and lessons learnt from documented blackouts in the period 19652006 as well as the best practices and tools that may be used to reduce the risk of future blackouts. The report also provided some high-level policy recommendations.

Finally, Lu et al. [5] study 37 blackouts that happened between 1965 and 2005, and proposes a classification of blackouts, which we use here in our analysis. The main suggestion brought by this analysis is to develop actions that can avoid to enter the fast cascade that cannot be stopped by operators.

However, none of the aforementioned studies cover the last decade period (i.e. from 2005 to 2016). Therefore, our work analyzes the main characteristics of blackouts for that period, completing in this way previous studies.

More recently, Bo et al. [12] analyze 23 representative blackouts of the period 1965-2012 with the objective of providing suggestions on the expansion and improvement of the Chinese power grid. The main recommendation resulting from this article is to manage the planning, construction, scheduling and emergency in a more unified way to prevent large-scale blackouts. However, given the focus of this work on the development of the Chinese grid, its analysis and recommendations are limited in extent to this particular case.

\section{Pre-conditions}

The pre-conditions are the set of state variables of the power system before the disturbance happens, when the system is in a stable state. In other words, pre-conditions define the context in which incidents happen. In our analysis, we used the main preconditions ${ }^{3}$ described in [5] and [10], namely: peak demand,

\footnotetext{
${ }^{3}$ The aging of equipment did not appear in the reports analyzed and hence it is not mentioned below.
} 
important equipment out of service, inadequate reactive power reserves and natural reasons.

We extend this list to include three new pre-conditions identified from our analysis, namely: dependency among regions, mismatch between scheduled and actual power flow and the $\mathrm{N}$ $\mathrm{k}$ reliability operating criteria (i.e. a metric of the reliability of the system). Fig. 2 summarizes the pre-conditions that preceded each of the eight ${ }^{4,5}$ analyzed blackouts, where pre-conditions are depicted within the square boxes below the blackouts abbreviations. We describe each of these pre-conditions in the following sections.

\subsection{Peak demand}

In previous periods, blackouts were usually happening during peak demand periods (usually winter and/or summer), when the system, being under stress due to the high loading, operates close to the operating and stability limits. However, as summarized in Fig. 2, 8 out of 9 blackouts of the period 2005-2016 happened under normal loading conditions. The only exception is the blackout in INDIA 12 in which the loading of the system reached respectively $99.7 \mathrm{GW}$ and $100.5 \mathrm{GW}$ load served prior to disturbance whereas the peak demand met at the time was around $110 \mathrm{GW}$.

Hence, the results of this analysis contrast with those of previous blackouts (i.e. of the period 1965-2005) for which peak demand was identified as the main pre-condition (i.e. around $65 \%$ of the 37 blackouts analyzed in [5] happened during peak conditions).

\subsection{Important equipment out of service}

Equipment can be out of service due to unexpected technical or supply problems (i.e. forced outage) or due to upgrading and maintenance works (i.e. planned outage). As highlighted in [6], one particularity of planned outages is that they are usually performed during normal or low loading periods (i.e. spring and autumn).

The absence of important equipment, as a result of (mainly planned) outages, played a key role in the development of many of the analyzed blackouts, as we discuss next. In TURK15, the backbone of $400 \mathrm{kV}$ transmission lines corridor between the Eastern and Western parts of the country was weakened due to planned outages of lines and series capacitors. In BRAZ11, a $500 \mathrm{kV}$ line was disconnected for maintenance purposes. In USA 1 1, 600MW generation in Baja California and two 230kV lines were under maintenance prior to the blackout. Five transmission lines were unavailable due to maintenance in CHILE11. In INDIA 12, several generating units and transmission elements (between the Northern, Western and Eastern regions) were under maintenance or under forced outage due to technical issues.

\footnotetext{
${ }^{4}$ For COLOM07 the list of pre-conditions is not exhaustive, given the lack of available information in the available reports.

${ }^{5}$ INDIA 12 encountered two very similar blackouts on two consecutive days, we thus treat the pre-conditions and initiating events as one blackout.
}

\subsection{Dependency among regions}

Dependencies on supply between regions of an interconnected network can have a great impact on the size and the speed of the blackout. In more detail, when an important disturbance happens, regions are often disconnected to avoid its propagation. However, in presence of strong dependencies on power supply, the deficit or excess of power generation can provoke a rapid collapse, leaving regions in an irrecoverable situation. We consider that one region is highly dependent, and consequently at risk, if the power imported is greater than $20 \%$ of its total consumption or close to the limit of import capability with power reserves issues. ${ }^{6}$ Notice that although the dependency among regions was not explicitly listed as a pre-condition in previous reports, it was frequently mentioned in the description of the blackouts contexts (e.g. [11] revealed that Southern Sweden/Eastern Denmark and Italy power systems were highly dependent on their neighbors previously to the two blackouts that followed). In this paper we decided to include it to highlight the risk of operating tie lines close to their limits especially when the loss of those could trigger very fast blackout.

As we can observe in Fig. 2, the dependency among regions turns out to be one of the main pre-conditions in our study since, as detailed next, 6 out of 9 blackouts faced this situation. In more detail, the Jakarta-Banten region of JAMALI system in INDO05 and the South Australia region in AUSTR 16 were importing respectively $21 \%$ and $32 \%$ of its consumption from neighboring regions. In CHILE 11 , the North Central region of the central interconnected system (SIC) ${ }^{7}$ was importing power mainly from only two areas, the South/East Ancoa and the Southern SIC. These dependencies created a deficit/excess of power after SIC separation.

In some blackouts these high dependencies between regions can be explained by the heterogeneous distribution of resources, for example hydroelectricity is not available everywhere. For instance, in TURK 15 the Eastern region was exporting a lot of hydroelectricity ( $42 \%$ of its production), most of it to the Western region that, without this potential, was importing $21 \%$ of its load demand. Similarly, in BRAZ11 (a country in which $70 \%$ of its production is from hydroelectricity) the North Eastern region was importing up to $36 \%$ of its load power demand, mostly from the hydroelectric resources in the South and Central regions of the country. Indeed the BRAZ11 blackout was initiated by a protection hidden failure at an hydro plant substation.

Finally, before both blackouts in INDIA 12, the Northern region was importing from the Western region between $12 \%$ and $15 \%$ from its load demand due to the unavailability of few thermal units that were under forced outage. Although this percentage of import is lower than the one from the 2003 Italian blackout that we took as reference, the fact that the Northern region was short in power reserves and that the import created congestion on the interconnection lines on the path across WesternEastern-Northern regions justifies this classification.

\footnotetext{
${ }^{6}$ This metric is in line with previous blackouts; for example before 2003 Italian blackout, Italy was importing $25 \%$ of its consumption, of which $21 \%$ were from Switzerland and France.

${ }^{7}$ In Chile there are four electrical interconnected systems operating independently of each other.
} 


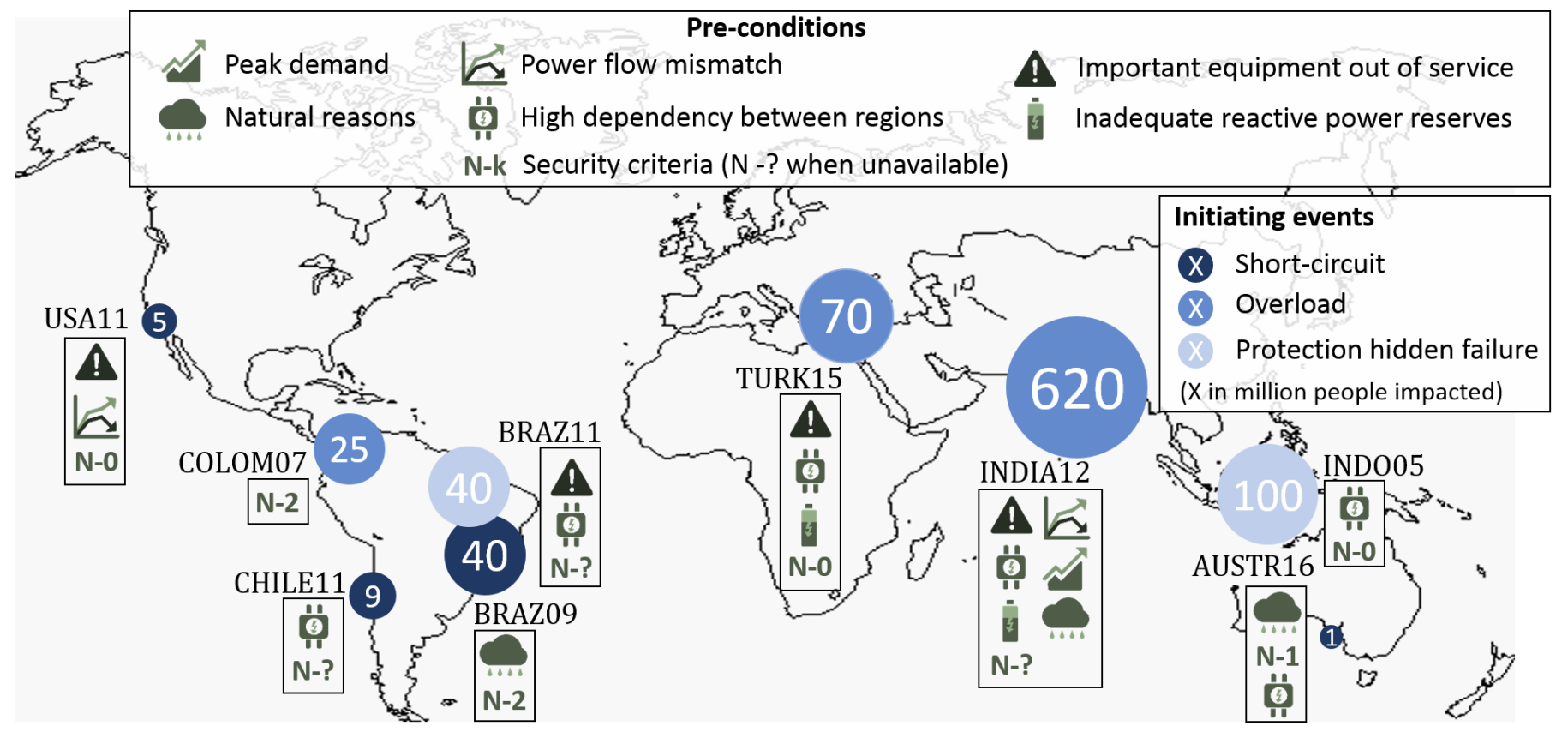

Figure 2: Location, million people impacted, pre-conditions and initiating events that triggered each blackout.

\subsection{Inadequate reactive power reserves}

The lack of reactive power reserves prevents the system from stabilizing the voltage and thus could lead to voltage instability or even collapse. Inadequate reactive power reserves are mentioned as pre-conditions in INDIA 12 and TURK 15 blackouts.

\subsection{Natural reasons}

Natural reasons can be an important factor in blackouts, especially extreme weather conditions like heavy rains, wind, or thunderstorms that can lead to short-circuits. For instance, BRAZ09 blackout happened during heavy rain and wind due to a thunderstorm. Both INDIA12 blackouts happened during the monsoon in the south of the country and created forced outages of some transmission devices. The AUSTR 16 blackout happened during a lightning storm.

Power system operators are aware of this risk and can take exceptional measures, like in BRAZ09 where the $765 \mathrm{kV}$ part of the system was operated to be N-2 secure (i.e. the loss of any pair of $765 \mathrm{kV}$ devices should not trigger a cascade). Nevertheless, in South Australia region, even with the high lightning risk, the operator assessed that there were no transmission line classified as vulnerable to lightning and hence he did not take more preventive measures than usual.

\subsection{Mismatch between scheduled and actual power flow}

The mismatch between the scheduled and actual power flows along interconnection lines is very risky because operators might not take the most suitable counter-measures in such emergency cases (i.e. there may be no contingency plan to handle such unexpected situation). Thus, before both INDIA 12 blackouts, significant mismatch between scheduled and actual power flows on interconnection lines were noticed. In USA11, the Western Electricity Coordination Council also observed unscheduled flows on major paths.

\section{7. $N$-k operating reliability criteria}

Reliability of power systems has been traditionally determined by the (deterministic) N-k security criteria. ${ }^{8}$ Fig. 2 depicts the N-k criteria at which power networks were operated prior to the blackout, and so provides an idea of the reliability of the system at the time of the initiating event. Most of transmission system operators (TSOs) must operate at least in compliance with the $\mathrm{N}-1$ criteria [33] so that the system can lose any of its devices and stay stable, i.e. with no propagation of the disturbance. However, because of unpredictable conditions or errors, the system sometimes cannot be kept within the N-1 limits. This was the case in the INDO05, USA 11 and TURK 15 blackouts, all triggered while the corresponding system was not $\mathrm{N}-1$ secure. Interestingly, the Turkish transmission system was not N-1 compliant even though both TSO (Eastern and Western) regions were individually $\mathrm{N}-1$ secure, which highlights the necessity of a close coordination between operators of interconnected networks.

Finally, it is worth to point out that in COLOM07 and BRAZ09 blackouts the systems were respectively totally and partly $\mathrm{N}$ 2 before the incident, which was nevertheless not sufficient to deal with the disturbance that followed.

\footnotetext{
${ }^{8} \mathrm{~A}$ power system is $\mathrm{N}-\mathrm{k}$ secure if the simultaneous loss of any set of $\mathrm{k}$ elements do not trigger a cascade.
} 


\subsection{Pre-conditions conclusion}

The main pre-conditions identified in our analysis are, first, the high dependency among transmission regions and second, the equipment out of service. The combination of these two conditions is particularly dangerous when interconnection lines are missing. Then any disturbance can overload the remaining lines and trigger the separation of the system which is at risk when regions are dependent on neighbors supply. Our findings are however different from those reported in [5]: for the period pre-2005, most blackouts happened in peak period whereas we observed the opposite tendency. Nevertheless, all blackouts considered in [5] happened in USA, Europe or Australia, whereas blackouts analyzed here mainly took place in South America or Asia (i.e. all except USA11, TURK15 and AUSTR 16). Hence, these systems have been developed at different times and continents, using different constraints and technologies, which makes the comparison difficult.

\section{Initiating events}

Initiating events are disturbances that trigger the cascade of events on the power systems, as illustrated in Fig. 1. The main initiating events ${ }^{9}$ are short-circuits, overloads and protection hidden failures. Fig. 2 shows the initiating events that triggered each of the nine blackouts, marked as the color of circle. We describe the occurrence of each of these events in the analyzed blackouts, according to available data, in the following sections.

\subsection{Short-circuits}

Short-circuits can happen due to natural reasons or errors, such as flash-overs caused by birds or wire insulation break downs. For instance, during BRAZ09, as a prevention from an ongoing thunderstorm, the Brazilian TSO decided to operate its $765 \mathrm{kV}$ network as N-2 secure. Nevertheless three short-circuits happened (on two main $765 \mathrm{kV}$ lines and on a $765 \mathrm{kV}$ busbar) almost simultaneously (within an electrical period). Additionally, the AUSTR 16 blackout was initiated by the combination of four single and one double phase-to-ground short-circuit faults that happened within 88 seconds and led to up to six voltage disturbances. Finally, the CHILE 11 blackout was triggered by a single-phase short-circuit on a switch. The short-circuit that triggered the USA11 blackout was due to a wrong maneuver of a technician while disconnecting a capacitor bank (i.e. it created an arc on a $500 \mathrm{kV}$ line that could not reconnect afterward because the phase angle difference was too large).

\subsection{Overloads}

When a power delivery device is loaded above its limits (i.e. overloaded), its protections can disconnect it to avoid the lagging of line or damaging the device. The INDIA 12 and TURK 15

\footnotetext{
${ }^{9}$ Although the loss of power plants is usually identified as a main initiating event in previous studies, here it is not included because it does not apply to any of the analyzed blackouts.
}

blackouts were triggered by overloads. In INDIA 12 , the shortcircuits that happened due to the monsoon weakened the circuit; then the initiating events were overloads in the heavily loaded North region for both blackouts.

In TURK 15, the disconnection of a line on the main corridor between the Eastern and Western regions due to overloading triggered a very fast separation of the two transmission systems. The COLOM07 blackout was initially triggered by a human error during a maintenance (i.e. an operator did not follow the sequence of maneuvers), which in turn led to the overload of a breaker that disconnected a substation that supplied the city of Bogota.

\subsection{Protection hidden failures}

Protection hidden failure is a malfunction of a protection device that trips whereas it should not have according to the settings of the system; or the opposite, that it does not trip whereas it should have.

The BRAZ1 1 blackout was triggered by the accidental opening of circuit breakers and the malfunction of a breaker failure protection, which in turn led to the disconnection of several $500 \mathrm{kV}$ lines. INDO05 blackout was triggered by the false signals from a protection device sent to Suralaya Power Plant.

\subsection{Initiating events conclusion}

We did not notice any major difference with the findings from studies of previous blackouts periods (e.g. [5]), as shortcircuits, overloads and protection hidden failures were also the main initiating events.

\section{Cascades of events}

In a blackout, the disturbance created by the initiating events propagates step by step and creates a sequence of events related to each other $[3,4]$. In this section, first, we classify the studied blackouts according to their speed. Then, we provide a discussion about the relationship between the presence of certain pre-conditions and the high speed of the blackout.

\subsection{Speed of the cascade propagation}

As shown in Fig.1, the cascade that follows the initiating events can often be divided into two successive phases, namely: $(I I)$ steady state progression and $(I I I)$ fast cascades. Unlike the fast cascade, the time between two events in the steadystate progression typically ranges from several minutes to several hours, which allows system operators to take countermeasures.

Clearly, the slower a cascade propagates, the more time operators have to decide which the most suitable decisions to take are. When the cascade is too fast, the defense plan of the system (automatic actions) is the only barrier that can stop the propagation. Since stability studies do not account for all interactions, even automatic secure protections cannot guarantee that the disturbance will not propagate beyond them. 


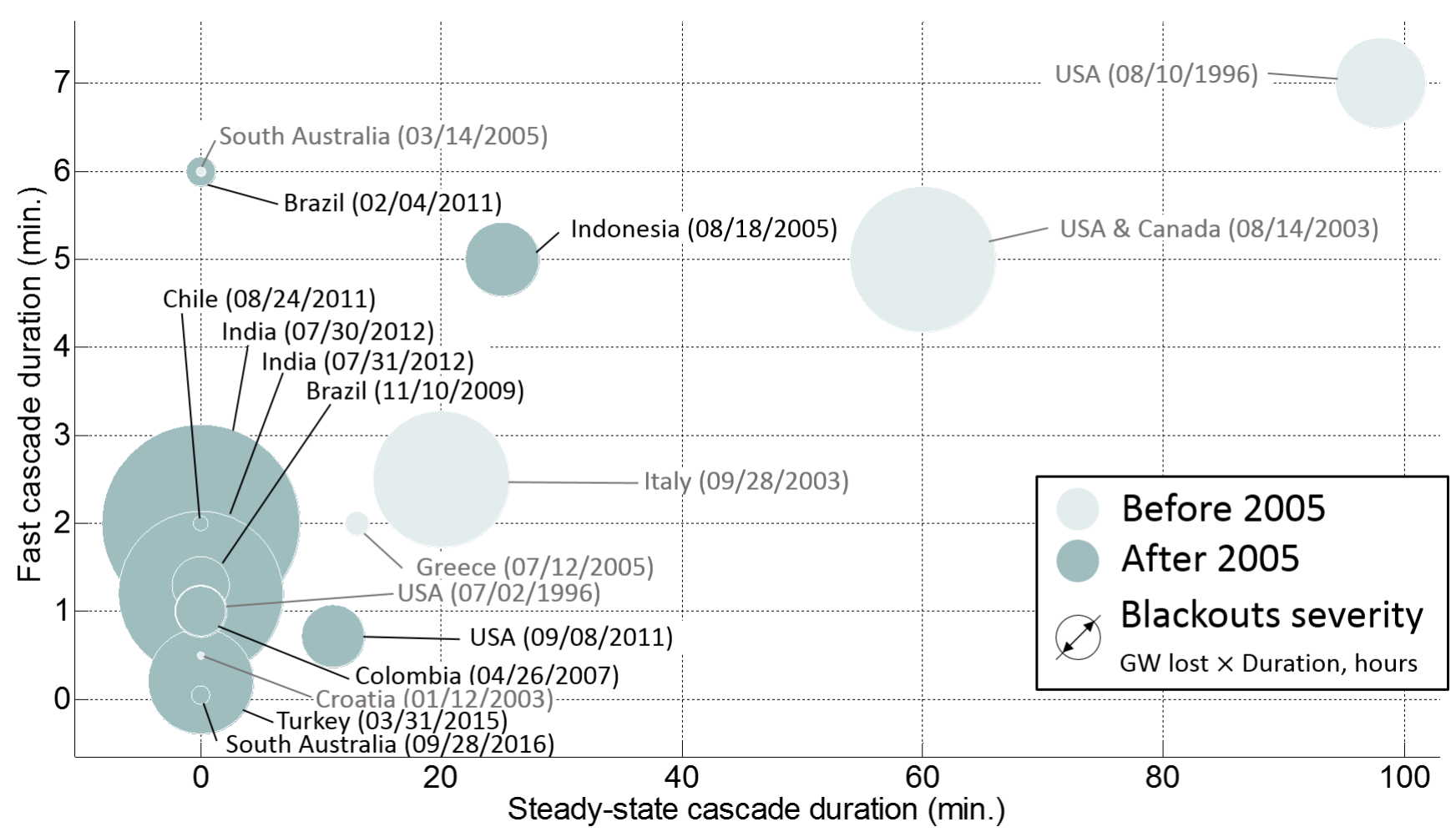

Figure 3: Steady-state progression duration vs fast cascade duration of blackouts prior to 2005 (pale circles) and blackouts after 2005 (dark circles). The diameter of the circles represents the severity of the blackout, computed as the maximum power lost times the duration of the total restoration.

Fig. 3 depicts the duration of each cascade phase and the severity of the blackouts. The horizontal axis shows the duration of the steady-state progression whereas the vertical axis shows the duration of the fast cascade. The size of the circles represents the severity of the blackout computed as the maximum loss of power consumption times the duration of the total restoration. The dark circles correspond to the nine blackouts whereas the pale circles correspond to seven blackouts that happened before $2005 .^{10}$ We can clearly see in Fig. 3 that most of the cascades of blackouts after 2005 (i.e. 7 out of 9) directly started with the fast cascade skipping the steady state propagation (i.e. most of the blackouts are concentrated on the left side of the graph). This high speed propagation can be caused by the large magnitude of the disturbance or by the proximity of the system state to the stability limits. The clearest case is TURK 15 where the point of no return was reached after only 1.6 seconds and thus operators could not do anything to stop the blackout. Nevertheless, in INDO0 5 and in USA 11 the steady state progression last 25 and 11 minutes respectively before the cascades accelerate by entering the fast cascade.

These findings contrast with those obtained for blackouts prior to 2005. For example, according to [7], more than half of the blackouts prior to 2012 in America and Europe were slow in progression. Likewise, the analysis in [4] concluded that most major blackouts from 1965 to 2006 were triggered by a single

\footnotetext{
${ }^{10}$ For blackouts prior to 2005 we use mainly data from [5] that selected those 7 blackouts for being the ones with better documented cascades.
}

initiating event and underwent a steady state progression before entering the fast cascade. Fig. 3 also supports this hypothesis by showing the presence of a steady state cascade in 4 out of 7 blackouts prior to 2005. In conclusion, our study shows that recent blackouts exhibit greater tendency to shorten or skip the steady-state progression than their precedents. The cause for this may be that these power systems were operating too close to the stability limits, which questions the trade-off between the economic dispatch and the network security. But as mentioned in Section 3.8, the differences in development and characteristics of the power systems are also other potential explanations for these observations.

\subsection{Discussion on the causes of the high-speed cascades}

In this section, we discuss the impact that some major preconditions (i.e. the cascade of overloads with large transfers of power, the separation of highly dependent regions and the malfunctioning of power monitoring equipment) have on the speed of the cascade that followed the initiating events.

\subsubsection{Cascade of overloads with large transfers of power}

A cascade of overloads starts with the loss of a power delivery element, i.e. a line or a transformer, which recursively leads to new overloads and disconnections as a result of the transfer of power to the remaining lines. Cascades of overloads are typically slow in progression, strongly depending on overload protections settings, and usually belong to the steady-state progression. In our analysis, INDO05 and USA11 blackouts followed 


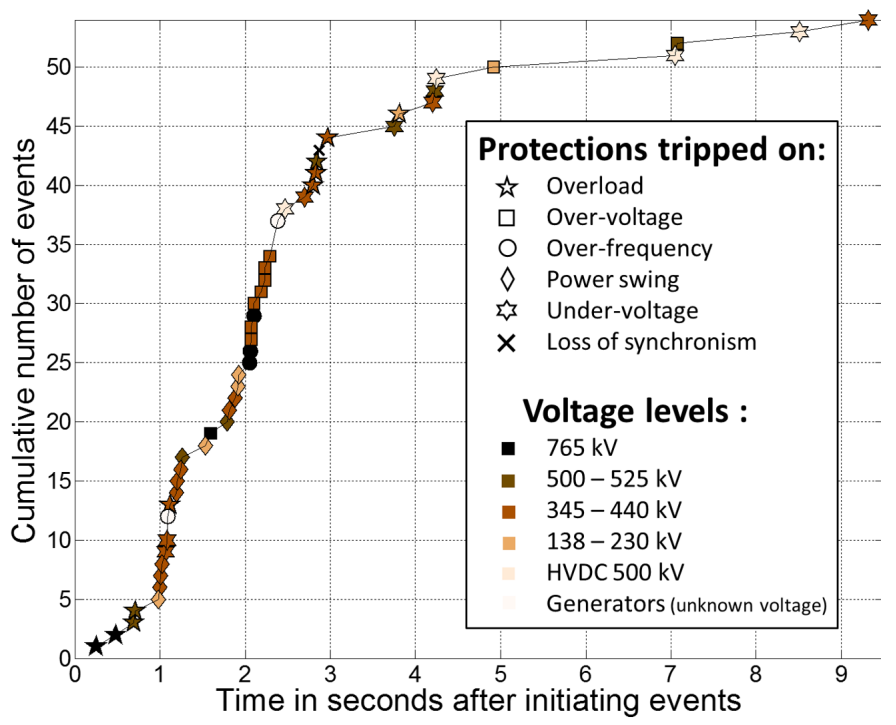

Figure 4: Cumulative number of elements disconnected during the first ten seconds (i.e. after the initiating event) of the BRAZ09 blackout. The plot symbols indicate the reason of the disconnection and the voltage level of the element.

this typical trend. In more detail, in INDO05, a cascade of overloads started after the initiating event as part of the steady-state progression phase. Likewise, in USA 11, a cascade of overloads (i.e. of transformers mainly) progressively increased the loading of a major path, making the over-current protections trip and eventually triggering the separation scheme of San Diego Gas \& Electricity and Southern California Edison networks.

Nevertheless, the speed at which the overloaded devices disconnect depends on the magnitude of the overload. Thus, if the overload generates a large transfer of power, it can, in turn, trigger an extremely fast cascade of overloads.

Sometimes, the large transfers of power are generated by initiating events that affect key components of the system. This was the case in COLOM07 where the disturbance at the main Bogota substation triggered a quick disconnection of ten overloaded lines and transformers. The resulting transfer of power initiated a fast cascade of overloads. In BRAZ09, during the first 5 seconds of the cascade, 50 elements (among which lines, transformers and generators) were disconnected from the grid. Fig. 4 shows graphically the evolution of the cascade of events of BRAZ09, plotting when the protections were triggered as well as the reasons for which they were triggered and their voltage level. We can observe in Fig. 4 how the disconnection of 3 parallel $765 \mathrm{kV}$ loaded lines, which were hit by quasisimultaneous short-circuits, started a very fast and violent cascade due to the large transfer of power that followed. The consequences of such large transfer of power made protections trip not only on overload but also on over-frequency, under and over-voltage.

At other times, large transfers of power are due to the contingencies on the transmission lines that connect highly dependent regions. For example in TURK 15, the transmission line corridor between the Eastern and the Western regions had some lines out of service, and the power flow between these two neighboring regions was important because of the dependencies on supply. These conditions increased the stress on the remaining interconnection lines and after the initiating event, a very fast cascade of overload started immediately.

Forced outages of generating units created a dependency between the North and its neighboring regions prior to INDIA 12 blackout. In addition, natural reasons created outages on interconnection lines which increased the loading of the lines to the North region and contributed to a fast cascade.

\subsubsection{Separation of highly dependent regions}

Although separation schemes are meant to mitigate the propagation of the instability by islanding healthy regions, they can also end up provoking the fast collapse of the system when regions are highly dependent on each other on supply or demand. In other words, it is highly likely that unbalanced regions collapse quickly after the separation.

Thus, in TURK 15 , the deficit $(21 \%)$ and excess (42\%) of production made the Western and Eastern systems collapse after their separation, which was a point of no return for the cascade. In AUSTR16, the South Australia region was importing $32 \%$ of its consumption and relied for almost half on wind farms. As a result of the voltage disturbances that followed the initiating events, the wind farms reduced by two their production and thus increased the imports of the regions by $23 \%$. The main tie lines automatic protections of loss of synchronism tripped because of this disturbance, which quickly led to a frequency collapse of the region. In BRAZ11, the Northeast region was importing $36 \%$ of its power demand and after the islanding of the region, the system ended up collapsing. In INDIA12, the fast cascade saturated the interconnection lines connected to the North region leading to under-frequency conditions. The other regions faced an over-frequency that disconnected the remaining generators. The same situation happened in CHILE11 where the North Central region was facing under-frequency and the Southern region an over-frequency after separation. Even for the two only blackouts with a steady-state progression, i.e. INDO05 and USA11, the separation of the system indeed initiated the fast cascades.

We clearly highlight that reaching separation schemes of regions that are significantly dependent on each other often leads to a very fast and unstoppable collapse of the system. The sharp change in power production or consumption caused by the separation is too fast and too large to be handled by the defense plans.

These conditions must then be identified depending on the importance of a connection for the stability of each region as well as the mechanisms that respond to the system disturbances. Criticality analysis of these power exchanges can be carried out to help designing countermeasures that should mitigate this risk. As an example, the primary reserves or even the defense plan could then be adapted to these special conditions. 


\subsubsection{Malfunctioning of power monitoring equipment}

Monitoring systems providing wrong information (or even failing), either prior or during the cascade of events, can dramatically impact the management of the contingencies (i.e. power system operators are left unaware of the real loading situation and their actions or inaction can worsen the cascades).

In INDIA 12 , respectively $25 \%$ and $50 \%$ of the Supervisory Control And Data Acquisition (SCADA) systems data was unavailable prior and after the initiating events. In addition, a $400 \mathrm{kV}$ line monitored value was frozen $30 \%$ lower than reality during the event and the line ended up overloaded. In USA11, the SCADA system of an important transformer suffered from accuracy issues which prevented operators to have a full awareness of the ongoing overload.

\subsection{Cascade conclusion}

The duration of the cascade of events, especially the steadystate progression, is a critical parameter as it is the time operators have to attempt to stop the cascade. As suggested in [5], mitigation actions should be taken before the fast cascade starts, i.e. before the system becomes uncontrollable with human time-scale actions. However, among the blackouts analyzed in this paper, only two entered the steady-state phase and for a short period of time. The other blackouts directly started with the fast cascade, just after the initiating event happened and thus they did not allow operators to take actions. The speed of the blackouts analyzed here differs from those of previous studies $[5,4,7]$. Nevertheless, the major cause of this speed was already mentioned in previous reports, e.g. [4]: power systems are operating closer to stability limits, under growing stress and power transfers over long distances are increasing.

The speed and the type of the cascades of events are highly related to the pre-conditions and the initiating events. We note that dependencies between regions that are likely to separate the system under emergency, may in turn trigger a very fast cascade due to the deficit/excess of power supply. We identified two main reasons for these transfers to be large (i.e. important enough to create a fast cascade of overloads), namely initiating events that affect key system components or transmission lines that connect regions highly dependent on supply.

\section{Conclusions}

We have analyzed 9 major blackouts that occurred between 2005 and 2016. The outcomes from our analysis revealed that blackouts from the last decade have a different anatomy than its precedents. In particular, peak demand, identified as a recurrent pre-condition in blackouts prior to 2005, is hardly ever found in our analysis. In contrast, nearly all the analyzed blackouts happened in maintenance periods of normal (or even low) loading since one of the main pre-conditions was that some important transmission delivery elements were out of service. Another pre-condition that we explicitly introduced in our analysis is the dependency on supply between regions because it significantly contributed to the stress of the system.
Our study finally shows that recent blackouts exhibit greater tendency to enter directly the fast cascade (i.e. skipping the steady-state progression) than in previous periods. Some explanations are mentioned and discussed such as the system separation, the large power transfers and their causes. It reveals that most systems were operating too close to the stability limits to withstand the disturbances.

The drawing of these common characteristics can be helpful for future work dealing with blackout analysis and mitigation. First, we observed that interesting scenarios for studying future blackouts could be power systems with normal loading but with important transmission lines or transformers missing. A multi-area system would be more appropriate in order to add large flows between regions and test the impact of the separation of the systems. Second, we also mentioned the possible risk brought by renewable energies (hydro power is highlighted in Section 3.3) whose potential is unevenly distributed [34, 35] and not necessarily geographically correlated with loads locations. If long distance transmission is needed, a special care should be taken to these power delivery systems to ensure security of supply. The planning should then take more into account the importance of interconnection lines in the stability of the system as well as the neighboring systems through coordination of planning and potential risks. A sudden separation of transmission regions should be considered and studied when assessing the risk of large scale blackout as the response of the system may lead to a very fast collapse.

From our conclusions, future works should also focus on the mitigation of dangerous conditions and thus work on day ahead or real time coordinated planning. Large-scale distributed coordination and optimization techniques coupled with new flexibilities brought by smart devices are tracks exploited in [36, 37], for example. This raises the difficult question of the trade-off between economic efficiency and security of supply in a context of high reliability of our society on electricity, with a nonnegligible risk of blackout and with growing integration of distributed and intermittent renewable energies.

\section{Acknowledgment}

We would like to thank Joko Muslim and Kevin Banjar Nahor for their help in finding and translating the Indonesian report [13].

\section{References}

[1] FERC and NERC staffs, Arizona-Southern California Outages on September 8, 2011: causes and recommendations, Tech. rep., Federal Energy Regulatory Commission (FERC) \& North American Electric Reliability Corporation (NERC) (2012). doi:10.1093/toxsci/kft047.

[2] National University System Institute for Policy Research, Blackout losses could top $\$ 100$ million (2011).

URL http://www.nusinstitute.org/press/in-thenews/Blackout-losses-could-top-100million.html

[3] Y. V. Makarov, V. I. Reshetov, A. Stroev, I. Voropai, Blackout prevention in the United States, Europe, and Russia, Proceedings of the IEEE 93 (11) (2005) 1942-1955. 
[4] IEEE Task Force on Blackout Experience, Mitigation and Role of New Technologies, Blackout experiences and lessons, best practices for system dynamic performance, and the role of new technologies, Tech. rep., IEEE Task Force (2007).

[5] W. Lu, Y. Besanger, É. Zamaï, D. Radu, Blackouts: Description, Analysis and Classification, in: WSEAS International Conference on Power Systems, Lisbonne, Portugal, 2006.

[6] R. Baldick, B. Chowdhury, I. Dobson, Z. Dong, B. Gou, D. Hawkins, H. Huang, M. Joung, D. Kirschen, F. Li, J. Li, Z. Li, C.-C. Liu, L. Mili, S. Miller, R. Podmore, K. Schneider, K. Sun, D. Wang, Z. Wu, P. Zhang, W. Zhang, X. Zhang, Initial review of methods for cascading failure analysis in electric power transmission systems, in: IEEE Power and Energy Society General Meeting '08, IEEE, 2008, pp. 1-8. doi:10.1109/pes.2008.4596430.

[7] M. Vaiman, K. Bell, Y. Chen, B. Chowdhury, I. Dobson, P. Hines, M. Papic, S. Miller, P. Zhang, Risk assessment of cascading outages: Methodologies and challenges, IEEE Transactions on Power Systems 27 (2) (2012) 631-641. doi:10.1109/TPWRS.2011.2177868.

[8] B. A. Carreras, D. E. Newman, I. Dobson, North American Blackout Time Series Statistics and Implications for Blackout Risk, IEEE Transactions on Power Systems 31 (6) (2016) 4406-4414.

[9] A. Atputharajah, T. K. Saha, Power system blackouts-literature review, in: International Conference on Industrial and Information Systems (ICIIS), IEEE, 2009, pp. 460-465.

[10] K. Yamashita, J. Li, P. Zhang, C. C. Liu, Analysis and control of major blackout events, 2009 IEEE/PES Power Systems Conference and Exposition, PSCE 2009 (2009) 2-5doi:10.1109/PSCE.2009.4840091.

[11] G. Andersson, P. Donalek, R. Farmer, N. Hatziargyriou, I. Kamwa, P. Kundur, N. Martins, J. Paserba, P. Pourbeik, J. Sanchez-Gasca, R. Schulz, A. Stankovic, C. Taylor, V. Vittal, Causes of the 2003 major grid blackouts in North America Europe, and recommended means to improve system dynamic performance, IEEE Transactions on Power Systems 20 (4) (2005) 1922-1928. doi:10.1109/TPWRS.2005.857942.

[12] Z. Bo, O. Shaojie, Z. Jianhua, S. Hui, W. Geng, Z. Ming, An analysis of previous blackouts in the world: Lessons for china's power industry, Renewable and Sustainable Energy Reviews 42 (2015) 1151-1163.

[13] Investigation Report on the Java-Madura-Bali Power System Blackout on 18 August 2005, Tech. rep., Ministry of Energy and Mineral Resources of the Republic of Indonesia (December 2005).

[14] C. A. Ruiz, N. D. J. Orrego, J. F. Gutierrez, The Colombian 2007 black out, 2008 IEEE/PES Transmission and Distribution Conference and Exposition: Latin America, T and D-LAdoi:10.1109/TDCLA.2008.4641845.

[15] P. C. Avella, Á. M. Cabra, N. D. Montoya, A. B. Barreto, L. S. Botero, J. Vargas, Evento del 26 de abril de 2007 en el sistema interconectado nacional sin colombiano, XM Compañía de expertos en mercados.

[16] M. Gutierrez, Colombian Blackout 2007, PAC World Magazine Blackout Watch (2009) 36-37.

[17] ONS, Análise da perturbação do dia 10/11/2009 às 22h13min, envolvendo o desligamento dos três circuitos da LT $765 \mathrm{kV}$ Itaberá - Ivaiporã, Tech. rep., Operador Nacional do Sistema Elétrico (ONS) (2009).

[18] J. M. Ordacgi Filho, Brazilian Blackout 2009, PAC World Magazine Blackout Watch (2010) 36-37.

[19] C. B. Antonio, P. Gomes, A. Guarini, F. Alves, N. Martins, D. Falcão, G. Taranto, C. Ribeiro, C2-214 CIGRE 2012 Lessons Learned in Restoration from Recent Blackout Incidents in Brazilian Power System TARANTO COPPE / UFRJ CEP : 22283-900, Tech. rep., CIGRE (2012).

[20] ONS, Análise da perturbaçâo do dia 04/02/2011 à 00h21min envolvendo os estados da região nordeste, Tech. rep., Operador Nacional do Sistem Elétrico (2011).

[21] Power System Operator of Central Interconnected System Chile (CDECSIC), Estudio para análisis de falla EAF 300/2011: Apertura intempestiva de los interruptores 52K1 y 52K2 de S/E Ancoa, Tech. rep., Power System Operator of Central Interconnected System Chile (CDEC-SIC) (2011).

URL http://www-old.cdec-sic.cl/admin/zip/c_1_s_ 6_ss_196_id_012480.zip

[22] CERC, Report on the Grid Disturbance on 30th July and 31st July 2012, Tech. Rep. 167, CERC (2012).

URL http://www.cercind.gov.in/2012/orders/Final_ Report_Grid_Disturbance.pdf
[23] Project Group Turkey, Report on Blackout in Turkey on 31st March 2015, Tech. rep., ENTSO-E (2015).

[24] AEMO, Update report: black system event in South Australia on 28 September 2016, Tech. rep., Australian Energy Market Operator (AEMO) (2016).

[25] Major Grid Blackouts of 2003 in North America and Europe, Panel session conducted at the Power Engineering Society General Meeting (2004).

[26] Power System Blackouts, Panel session conducted at the Power Systems Conference and Exposition (2006).

[27] J. Paserba, P. Kundur, Guest editorial - power grid blackouts remembering and fighting grid failures, IEEE Power and Energy Magazine 4 (5) (2006) 16-21.

[28] P. Pourbeik, P. S. Kundur, C. W. Taylor, The anatomy of a power grid blackout - root causes and dynamics of recent major blackouts, IEEE Power and Energy Magazine 4 (5) (2006) 22-29.

[29] J. E. Dagle, Postmortem analysis of power grid blackouts - the role of measurement systems, IEEE Power and Energy Magazine 4 (5) (2006) 30-35. doi:10.1109/MPAE.2006.1687815.

[30] P. Pourbeik, M. Bahrman, E. John, W. Wong, Modern countermeasurus to blackouts, IEEE Power and Energy Magazine 4 (5) (2006) 36-45. doi:10.1109/MPAE.2006.1687816.

[31] L. Wang, K. Morison, Implementation of online security assessment, IEEE Power and Energy Magazine 4 (5) (2006) 46-59. doi:10.1109/MPAE.2006.1687817.

[32] S. H. Horowitz, A. G. Phadke, Blackouts and relaying considerations relaying philosophies and the future of relay systems, IEEE Power and Energy Magazine 4 (5) (2006) 60-67. doi:10.1109/MPAE.2006.1687818.

[33] A. Pinar, J. Meza, V. Donde, B. Lesieutre, Optimization strategies for the vulnerability analysis of the electric power grid, SIAM Journal on Optimization 20 (4) (2010) 1786-1810.

[34] C. L. Archer, M. Z. Jacobson, Evaluation of global wind power, Journal of Geophysical Research: Atmospheres 110 (D12).

[35] M. Šúri, T. A. Huld, E. D. Dunlop, H. A. Ossenbrink, Potential of solar electricity generation in the european union member states and candidate countries, Solar energy 81 (10) (2007) 1295-1305.

[36] R. Faranda, A. Pievatolo, E. Tironi, Load shedding: a new proposal, IEEE Transactions on Power Systems 22 (4) (2007) 2086-2093.

[37] D. Andersson, P. Elmersson, A. Juntti, Z. Gajic, D. Karlsson, L. Fabiano, Intelligent load shedding to counteract power system instability, in: Transmission and Distribution Conference and Exposition: Latin America, 2004 IEEE/PES, IEEE, 2004, pp. 570-574. 